\title{
Correction to: Ground penetrating radar use in flood prevention
}

\author{
Sylwia Tomecka-Suchon ${ }^{1}$ D
}

Published online: 4 October 2019

(c) Institute of Geophysics, Polish Academy of Sciences \& Polish Academy of Sciences 2019

\section{Correction to: Acta Geophysica https://doi.org/10.1007/s11600-019-00353-8}

The original version of this article unfortunately was not the last version of this article. The updated version is given below.

Abstract The main goal of the work is to create an automatic method of locating weak zones within flood embankments structure based on ground penetrating radar (GPR) measurements. The presented research shows the possibilities of using advanced methods of GPR signal processing and its analysis with the help of signal attributes for detecting zones threatening the stability of the structure of flood embankments. Obtained results may help in quick detection of potential weak zones of the embankments, and consequently give means to ameliorate them, which may prevent damage to the embankments during rise in the level of river water. The presented analyses were carried out on GPR data obtained for the flood banks of the Rudawa river (Kraków, Poland) in the area of their visible degradation. The use of signal attributes such as energy, instantaneous frequency, similarity, curvature gradient and dominant frequency, allowed initial indication of anomalous zones threatening the stability of embankment. Advanced processing supported by the use of advanced filters such as GLCM, Grubbs and Convolve Prewitt helped in the analysis of the structure of the embankments. Artificial neural networks (ANN) in the supervised and unsupervised variants were used to perform the automatic classification of weakened zones within the embankments. The results demonstrated the usefulness of

The original article can be found online at https://doi.org/10.1007/ s11600-019-00353-8.

Sylwia Tomecka-Suchoń

tomecka@agh.edu.pl

1 Faculty of Geology, Geophysics and Environmental Protection, AGH University of Science and Technology, Mickiewicza 30 Ave., 30-059 Kraków, Poland
GPR geophysical method through integration of ANN in the analysis of the data.

Keywords GPR · Attribute analysis · Embankments · Neural networks

\section{Introduction}

The work is aimed at creating an automatic method of locating weak zones within flood embankments structure based on GPR measurements.

The GPR method in the study flood embankments has been extensively described in the scientific literature (Gołębiowski and Małysa 2018a, b; Anchuela and Pueyo 2018; Lój et al. 2018; Tanajewski and Bakuła 2016; Perri et al. 2014; Gołębiowski et al. 2012; Słowik 2011; Xu 2010; Di Prinzio et al. 2010; Jarzyna 2010; Mori 2009; Marcak et al. 2005). Antoine et al. (2015) experimented the application of GPR method in the study and monitoring of the lateral canal of the Loire river (Saint Firmin, $80 \mathrm{~km}$ South East of Orléans). The results led to the delineation of weak unconsolidated zone within the embankment. However, there are still many unresolved problems.

Essentially, advance statistical analysis in the form of artificial neural network (ANN) operation was performed on the measured data and its attributes in order to enhance its better interpretation. A special method using ANN was developed for the detection and location of anomalies. The theory and applications of this method is presented by Tadeusiewicz (2015), Szymczyk et al. (2014), Szymczyk et al. (2015a, b), Tomecka-Suchoń (2012) and Tomecka-Suchoń et al. (2019).

One of the main problems that arise with prospective flooding after a heavy rainfall is the strength of embankments to withstand the flood. When the high flood water comes, the only hope is that the embankments will withstand and the water will not overflow the cultivated fields and human settlements that lie behind them.

In a basic concept, embankment fundamental structure is made of the central core, the filters part, support fill zone and 
cement-bentonite grouting zone. Each of these components has different material properties and functionality; thus, core is composed of fine-grained soils such a clays, clayey sands and silty sand, which function is to control the seepage within the embankment. Filters are usually sand and gravelly sand and or sandy gravel which constitute a protection against material transport from the core; support fill provides stability for the embankment and is made of coarse rock-fill, and the cement-bentonite grouting zone functions as protection of the embankment from under-seepage occurrence.

Most of the existing embankments in Poland were built many years ago. They have already confirmed their usefulness during floods that have occurred in the past, but this fact does not guarantee that the embankments will prove effective also during the floods that will come in the future. The external inspection of the embankment does not reveal the greatest threats, which are potentially zones of weakness inside the embankment. The origin of these zones may be different-for example, there are burrows of animals hollowed inside embankment which weaken its structure, erosional effects and sometimes also errors made during the construction of the embankment.

It is worth emphasizing that the zones of loosening often occur at the base of the structure of the embankment, sometimes even close to the foot of the embankment; so when the water of the flood begins to wade through them over time, the typical methods of flood defenses, consisting of laying of sand bags on the shaft's crown, may not be ineffective. This may be due to the water that goes to the basal part, destroying the structure of the embankment's interior at the same time.

Rudawa is a river in Poland (the left tributary of the Vistula river), like other rivers, that has repeatedly changed its bed. Before regulation in 1910-1912, Rudawa crossed Krakow with several branches. Therefore, in its direct vicinity, it has a number of oxbows, some of which are no longer visible to the naked eye. In previous years (before regulation), oxbows could be easily seen. As it can be seen in the attached photograph (Fig. 1), remains of old oxbows, with a specific shape of hollows in which the characteristic vegetation is present (alder, willow and other plants typical of wetlands), are still present near the banks of the river. During the regulation of the river, the area was leveled and oxbow was buried. However, they did not disappear completely; they were no longer visible, which made them potentially dangerous due to variations in material properties of the ground. A characteristic feature of the oxbow is the high content of water accumulated in the ground. This is not a prima facie statement. It has been confirmed in practice. Among other, the builders in the city of Krakow during the earthworks in the area near Rudawa river encountered oxbow beneath ground. The oxbow, due to its high humidity, threatened the stability of the building structure, which forced the builders to perform additional unpredictable works aiming to excavate the material in that place.

Of particular significant were the floods in May 2010 and 2013 when there were heavy rainfalls. This proves the presence of leaks and loosening of the ground in the embankments structure. Detailed research and location of such loosed and weak zones seem to be necessary for further work to prevent the future occurrence that may arise from the zones. The detailed location of possible leaks will allow for the proper targeting of works and effective safeguards and circumvent the problem.

The most important factor for analysis of the possibility of the anomalies in the structure of the embankment detection using electrical and electromagnetic techniques is the assessment of alteration of the electromagnetic properties of the ground caused by the presence of weak zones. Importantly, the relative dielectric permittivity $\varepsilon_{\mathrm{r}}(-)$, electrical
Fig. 1 Satellite view to area of research. Remains of old oxbows with specific vegetation are marked by yellow dashed circle. Source: https://www. google.com/maps)

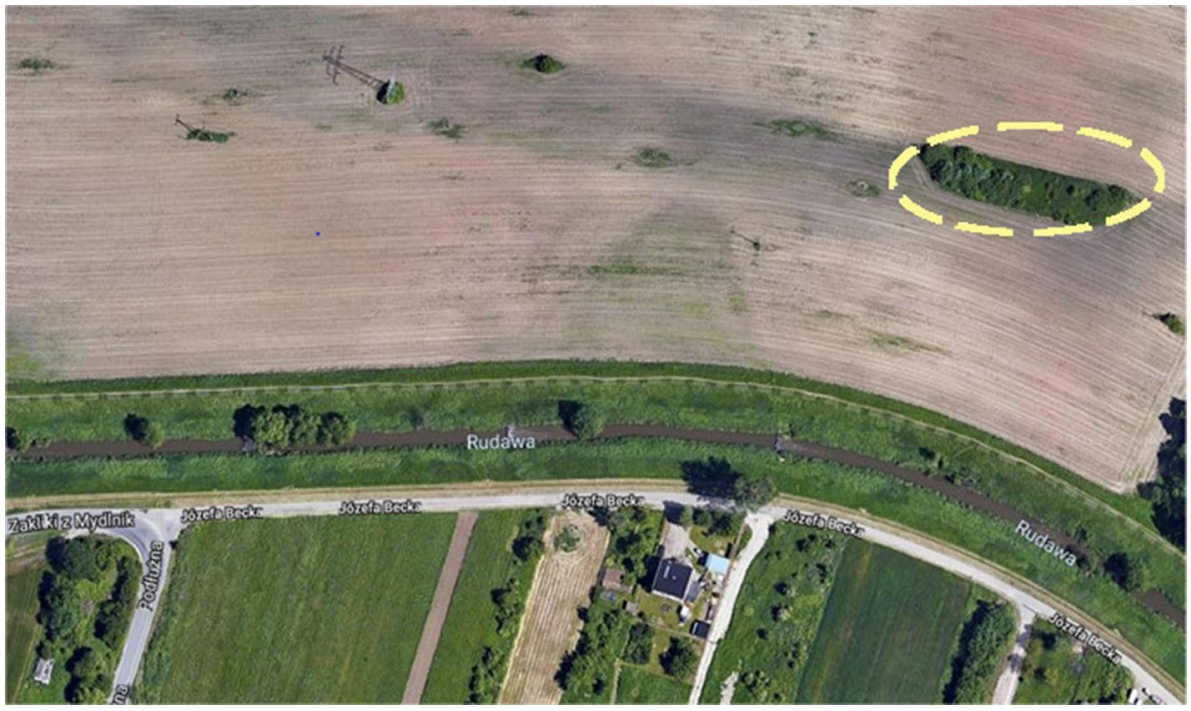


conductivity $\sigma(\mathrm{S} / \mathrm{m})$ and a seemingly negligible relative magnetic permittivity $\mu_{\mathrm{r}}(-)$ which is usually taken as 1 are valuable parameters needed for such a analysis.

The material most often used for the construction of levees is clay sands and sandy dust. Due to the high attenuation of the GPR signal, resulting from high conductivity of clay material, the results of GPR measurements carried out on flood embankments are usually difficult to interpret. This article aims to present the methodology of GPR signal processing which allows the separation of anomalous zones within flood embankments.

To detect anomalies in the structure of the embankment, it was decided to use ground penetrating radar (GPR), which can reveal anomalies in the structure of the embankments.

\section{Localization of study area}

The GPR measurements were carried out on Rudawa river embankments in Wola Justowska-a suburb of Krakow on the Beck Street along few profiles (example of one profile in Fig. 2a). Today, it is known that Rudawa has changed its course. The direction of the current river bed is straight due to the adjustment as a result of the embankment (Eanczont et al. 2015). This scenario contradicts the situation in the past particularly before the nineteenth century when the river meandered and caused flooding. The upland within this zone served as the ground for the burial of dead people after outbreak of cholera epidemics.

During the construction of the embankments, the Rudawa's old river beds were dug. Until now, the course of the Rudawa river bed could be determined based on descriptions or based on old photographs (Fig. 2b).

\section{Method of study}

The ProEx GPR system manufactured by MALA Geoscience (now ABEM/MALA) was used with $250 \mathrm{MHz}$ shielded antenna with mean resolution of approximately $0.1 \mathrm{~m}$ and its maximum depth penetration is approximately $10 \mathrm{~m}$ which allows to visualize the loose zones in Rudawa river embankment. Exemplary radiogram for one of the profile of the measured data no 1 is presented in Fig. 3.

All radargrams were processed using ReflexW program (Sandmeier 2012) with the following procedures (Annan1999; Everett 2013): phase correction, time zero correction, amplitude declipping, dewowing, DC-shift, gain, background removal, Butterworth filter, deconvolution (improves the vertical resolution) and smoothing.

Wide angle reflection and refraction (WARR) profiling carried out in the studied area (Fig. 4a) gave velocity of direct ground wave as $0.0754 \mathrm{~m} / \mathrm{ns}$ and velocity of reflected wave as $0.0426 \mathrm{~m} / \mathrm{ns}$ (which depict the high water saturation of examined medium). In such situation, for the time-depth conversion, $v=0.0754 \mathrm{~m} / \mathrm{ns}$ was used in the data analysis, because considered anomalies occur above $50 \mathrm{~ns}$ (reflector registered on such a depth).

The zones of weakness in the embankment, regardless of whether they are dry or filled with water, caused an increase in reflectivity. It means that on radargram, it shows as larger amplitudes of registered signal. Randomly distributed highamplitude anomalies probably indicate weak zones. These zones are prone to seepage or pathway for the river course in the nearest future.

By standard method of interpretation of GPR, may not be effective for recognizing the weak zones that are prone to seepage or pathway for water. Hence, attribute computation (a)

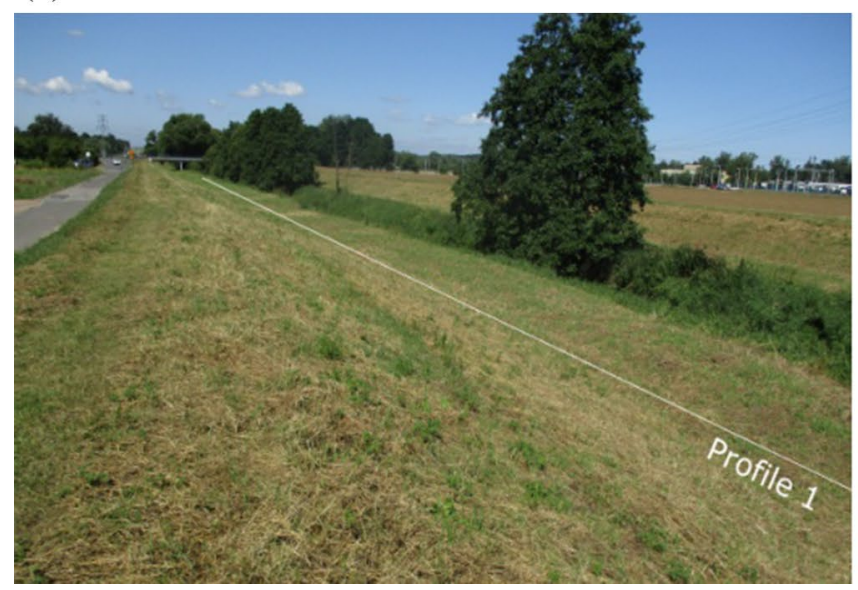

(b)

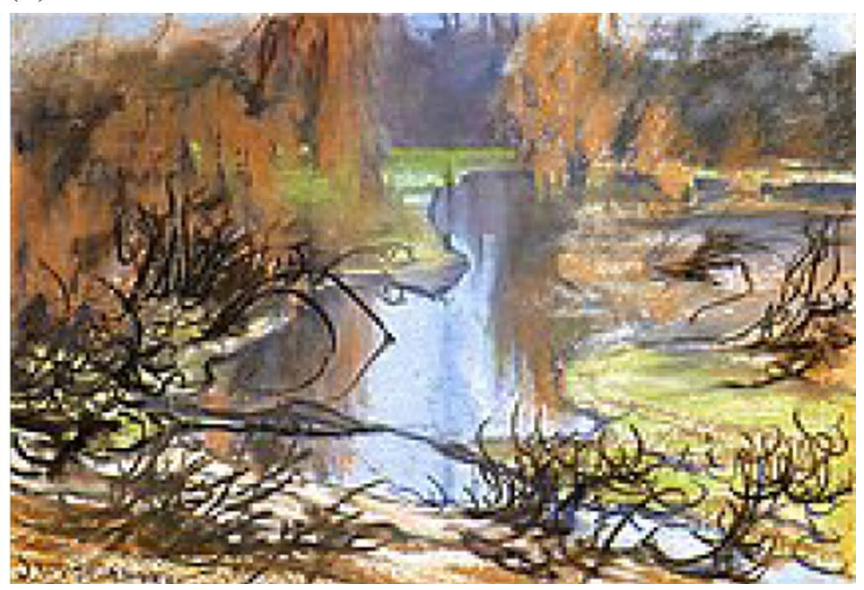

Fig. 2 a View of the plain of Rudawa river embankments where measurements were made (profile 1). b Artistic impression of the Rudawa river landscape after Stanisław Wyspiański 


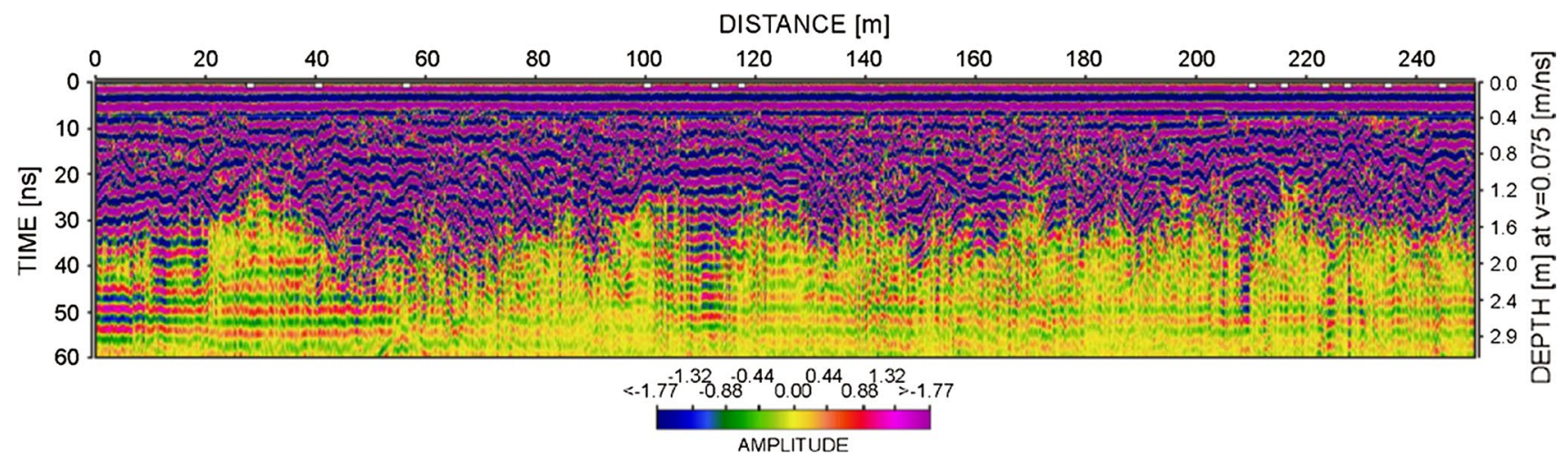

Fig. 3 Radargram of one of the profile (no. 1) of flood embankments in the vicinity of the Rudawa river with the distribution of the anomalies from the loosed zones

(a)

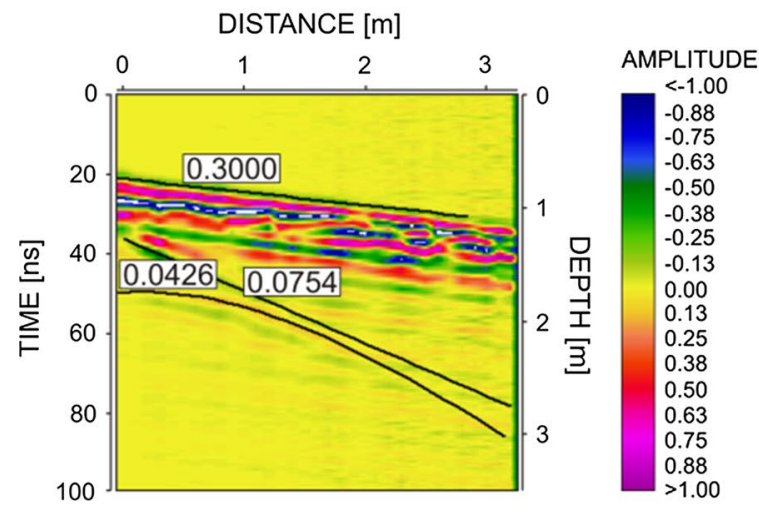

(b)

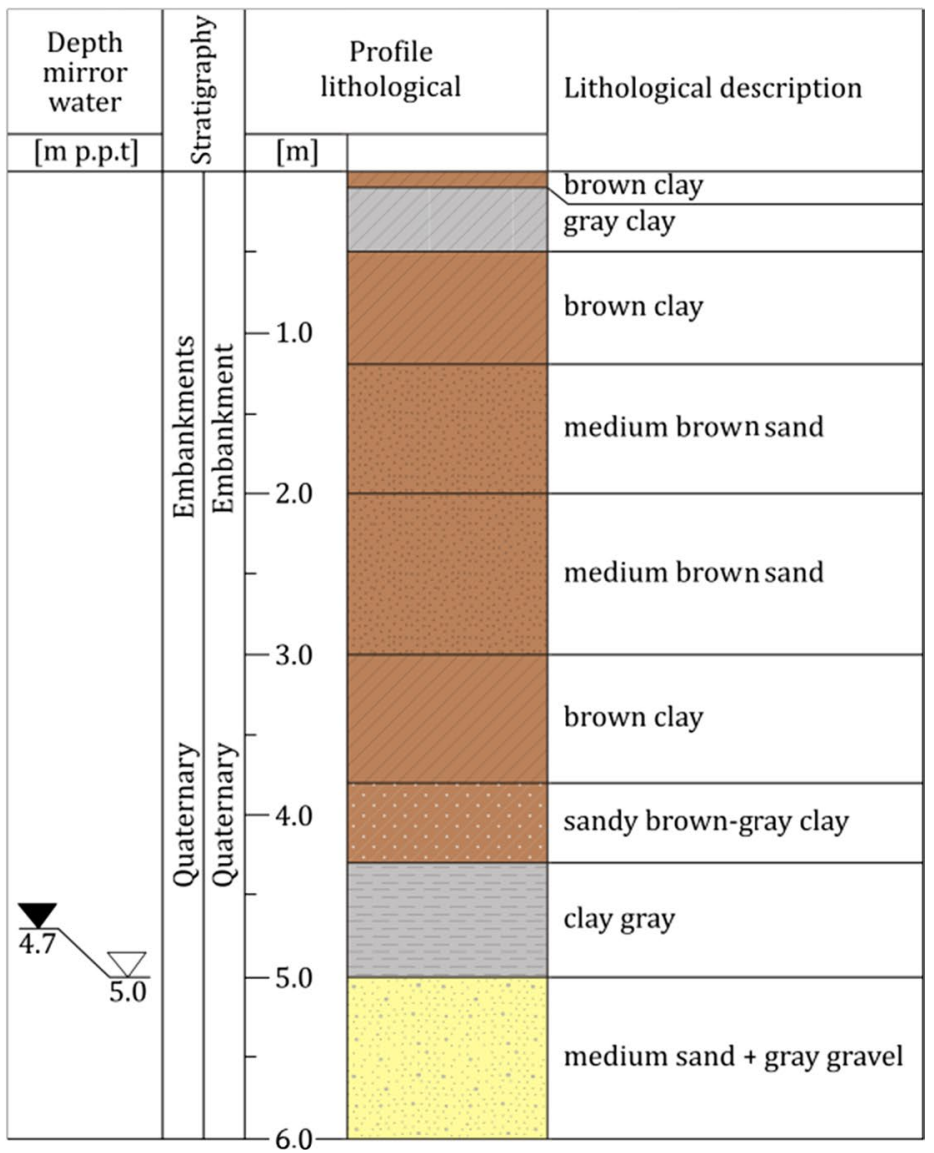

Fig. 4 a WARR profile in the area of study and $\mathbf{b}$ lithological profile from study area. Modified Sieinski et al. (2015)

of the GPR signal may enhance the identification of the inherent properties of the embankment materials. Moreover, output of the attributes may serve as valuable input in the use of ANN.

Although the displayed information on the processed radargram may be visible and provide interpretative deduction, this is subjective to different interpreters. Then, to overcome the subjectivity, advance processing in the form of signal analysis (attributes) was made to provide information that may not be discernable and subjective. Output of this analysis may serve as input in the use of neural networks for better interpretation.

Examination of embankments with the use of GPR data requires the use of many techniques of data processing and 
analysis. In the present time, there are a lot of possibilities. However, we can replace human eyes with more precise methods of artificial intelligence. This is necessary because the anomalies recorded on radiograms are not always legible enough to read only with the eyes.

The signal analysis was realized by using OpendTect software (DGB Beheer BV 2019). OpendTect is a wave form data interpretation software system for post-processing, visualizing and interpreting data for fast-track development of innovative interpretation tools.

In a task of classification or recognition of patterns, essential steps of analysis and removal of natural redundancy of source signal which allows for better identification through the use of statistical analysis are important. Thus, a semantic, adequate and objective interpretation may be achieved. The above described process is known as ANN.

To engage the use of ANN, input data are required as the entry data. In this situation, we used the attributes of GPR signals calculated from the field data.

Attributes include any quantitative transformation of data made from GPR survey. The application of this attribute allowed for an improved interpretation of the GPR data.

The following signal attributes were calculated using OpendTect: the energy attribute, the instantaneous frequency, similarity, attributes in the group of texture that return statistical properties of a gray-level co-occurrence matrix (GLCM), curvature gradient, Grubbs filter threshold, Convolve Prewitt and dominant frequency.

The Energy attribute calculates the squared sum of the sample values in the specified time-gate divided by the number of samples in the gate. The energy is a measure of reflectivity in the specified time-gate. The higher the energy, the higher the amplitude. This attribute enhances, among others, lateral variations within events.

The signal energy in the signal $x(t)$ is given by:

$E=\int_{-\infty}^{\infty}|x(t)|^{2} \mathrm{~d} t$

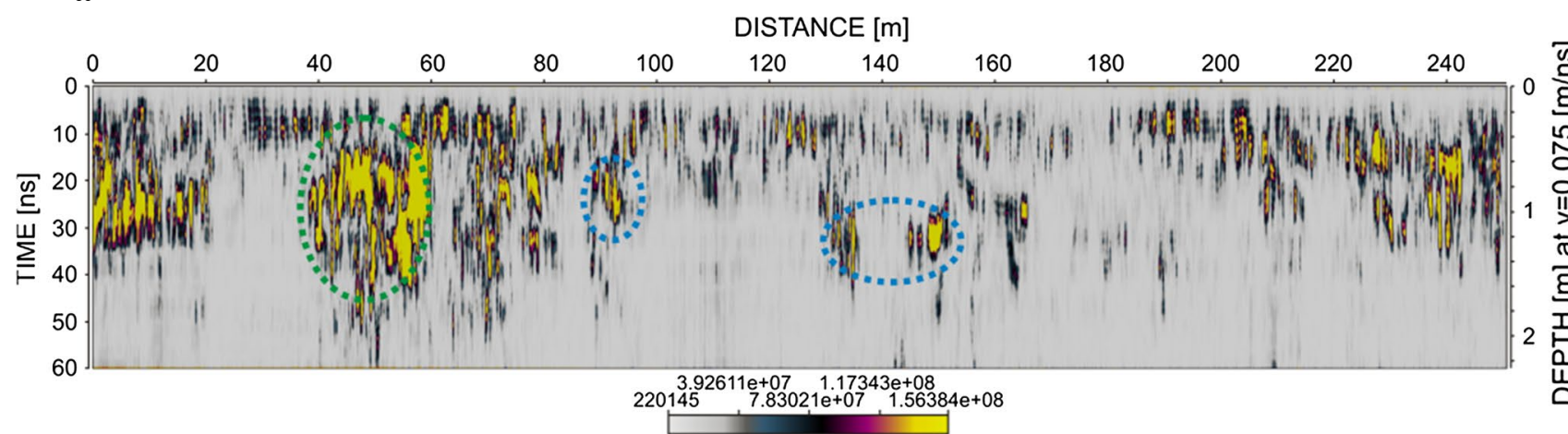

Energy attribute is used in GPR method for wide range of purposes, examples of usage can be found in Golebiowski et al. (2018) and Zhao et al. (2013).

In this study, energy attribute highlights the maximum amplitudes of the reflected wave signal that can be correlated with the loosed zones (Fig. 5). This is due to high dielectric constant of loose zones compared to the surrounding, caused by higher content and filtration of water in such a zones. What we consider as main loosed zone is marked by green dashed circle (Fig. 5). On the other hand, high energies can also be associated with different materials used for building of dike. Based on historical information and visible signs in the site morphology we can predict that anomalies marked by blue dashed circles in Fig. 5 as being connected with geomorphological deflection induced by the beneath buried oxbow phenomenon. Signature of observed anomalies is deflected in shape, because we can observe only reflection from the top part of flanks of buried oxbows due to high attenuation of electromagnetic wave (signal simply can not reach bottom of buried oxbow). High energy in this case can be connected with strong contrast of dielectric constant between flanks of buried oxbow and material which fill it up.

Instantaneous attribute-attribute that returns a value at a single sample location is computed sample by sample, and represents instantaneous variations of various parameters. Instantaneous values of attributes such as trace envelope, its derivatives, frequency and phase may be determined from complex traces (Taner et al. 1979; Taner 2001).

The instantaneous frequency attribute responds to both wave propagation effects and depositional characteristics; hence, it is a physical attribute which can be used as an effective discriminator.

Among its applications include: fracture zone indication, since fractures may appear as lower frequency zones and bed thickness indicator. Higher frequencies indicate sharp interfaces such as exhibited by thinly laminated shales, lower frequencies are indicative of more massive
Fig. 5 The Energy attribute highlights the maximum amplitudes of the reflected wave signal that can be correlated with the loosed zones (yellow areas). Main loosed zone is marked by green dashed circle.
Anomalies probably connected with buried oxbows are marked by blue dashed circles 
bedding geometries, e.g., sand-prone lithologies (Nemytova et al. 2012).

Instantaneous frequency (Fig. 6) depends on the geometrical layout of the reflex and on the interference. It does not depend on the signal energy. In our case, it enhances interfaces between three GPR facies marked by white lines in Fig. 6. Due to the noise level, those interfaces can be set only for part of the profile. Area considered as loose zone is marked by black dashed circle.

Examples of application of aforementioned attribute for GPR prospecting can be found in Bradford and Wu (2007).

Similarity is a form of coherency that expresses how much two or more trace segments look like. A similarity of 1 means the trace segments are completely identical in waveform and amplitude.

A similarity of 0 means they are completely dissimilar. It is used to visualize abrupt pinch-out, erosional incisions and lateral variable lithofacies.

Similarity attribute can be used to emphasize the variability of neighboring data (Boniger and Tronicke 2012), and thus allows strengthening the edges naturally and artificially generated degradation zones within embankment structure. Theory and applications of similarity for seismic data are described by Chopra (2007) and Chopra and Alexeev (2005).

The result of the similarity attribute (Fig. 7) shows continuous coherent reflections depicted by the white patches, which could be correlated with highly saturated soil or the appearance of stratification. Similarity is rather high in the area considered as main loosed zone because the surfaces of cracks present in this zone that could cause dissimilarity have dimensions below the resolution of the antennas used during measurements. Therefore, signal distorted by the loosed zone is distinguished from the environment; internally, however, this zone is observed as "homogeneous" due to aforementioned not good enough resolution. Sectorally, the largest high anomaly of similarity attribute can be observed in the zone marked by yellow dashed circle. The area marked in this way can be tied to a large homogeneous part of the embankment.

Attributes in the group of texture that return statistical properties of a gray-level co-occurrence matrix (GLCM) (Chopra and Alexeev 2005; Hall-Beyer 2012) characterize the texture of an image by calculating how often pairs of pixel with specific values and in a specified spatial relationship occur in an image, creating a GLCM, and then

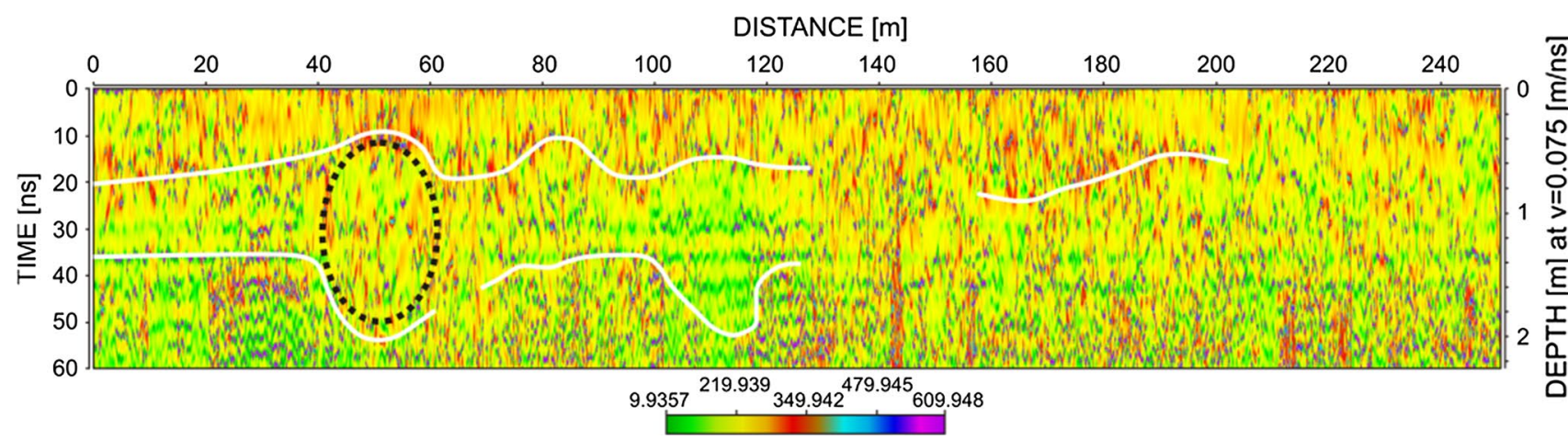

Fig. 6 Instantaneous frequency computed for profile 1. It enhances interface between GPR facies (marked by white lines). Main loosed zone is marked by black dashed circle

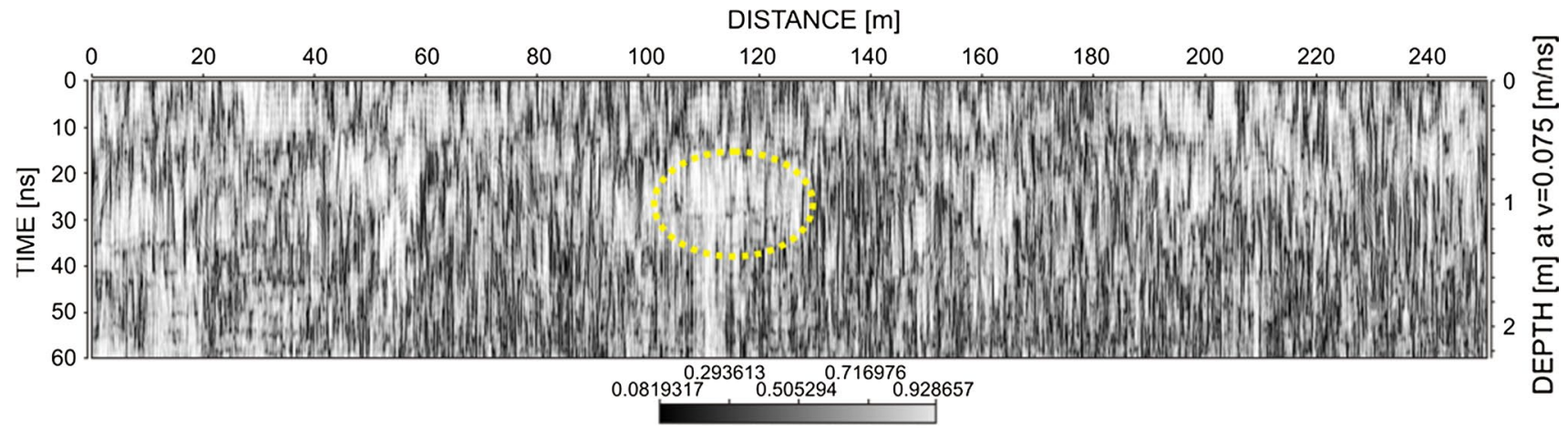

Fig. 7 Similarity computed for profile 1. Shows continuous coherent reflections depicted by the white patches, which could be correlated with highly saturated soil or the appearance of stratification. Largest homogenous zone is marked by yellow circle 
extracting statistical measures from this matrix. GLCM texture considers the relation between two pixels at a time, called the reference and the neighbor pixel. The attribute response is calculated in two steps: First, the GLCM is computed for an area (volume) around the evaluation point. Secondly, a statistical property from the GLCM is returned.

In the literature, we can find few examples of using GLMC for GPR signal enhancement (McClymont et al. 2008; Catakli et al. 2011; Zhao et al. 2016).

GLCM attribute is used in facies analysis. It can be done both in supervised and unsupervised approach.

The GLCM texture analysis (Fig. 8) confirms that the geological compositions in which the embankment was made are of different materials. We can observe (white dashed circle in Fig. 8) that part of embankment which is horizontally stratified and build form homogenous material is enhanced by GLCM median filter (extreme amplitude values). It follows that GLCM median filter can be used as an indicator of zones with good mechanical properties inside the embankment structure. Additionally, based on geological data from a geotechnical borehole, located in the research area (Fig. 4b), considered GLCM anomaly can be linked with the presence of clay material, as in the case of similarity attribute.
An integrated curvature and curvature gradient analysis suggest that curvature might help define areas of enhanced potential to form tensile fractures, whereas curvature gradient might help define zones of enhanced potential to develop shear fractures (Gao 2013). It can be potentially applied to differentiate fracture mode, to predict fracture intensity and orientation, to evaluate fracture volume and connectivity, and to model fracture networks.

Curvature gradient might help define zones of enhanced potential to develop shear fractures. It depicts the geometry of reflectors in the subsurface.

Curvature is also defined as the inverse of the radius of the circle that is not only tangent to the surface but that also fits the surface (Rich 2008; Rich and Marfurt 2013).

The curvature gradient has shown anomalies that are suggestive of the oxbows which existed in this area many years ago (marked by dashed white circles in Fig. 9). These oxbows are thought to have been backfilled with different materials with different provenance. These findings can contribute toward reconstruction of the paleoenvironment in which Krakow was made.

In this attribute, traces of the geomorphological deflection above oxbows of the Rudawa river were well-delineated than as shown in the field data. Zones have been

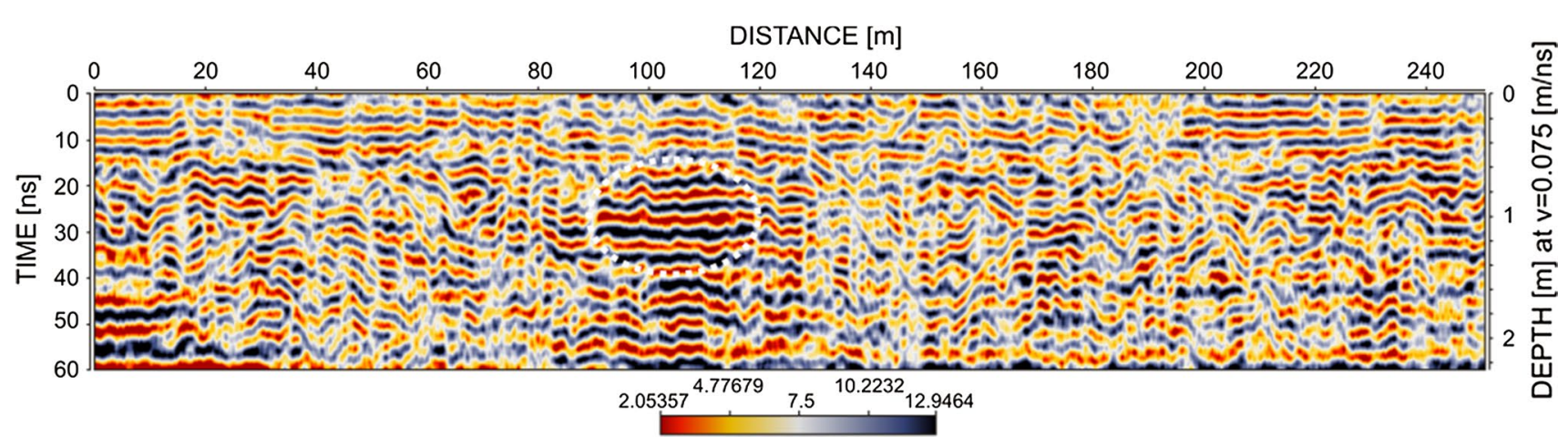

Fig. 8 GLCM mean computed for the profile no. 1. The largest homogenous zone marked by white dashed circle

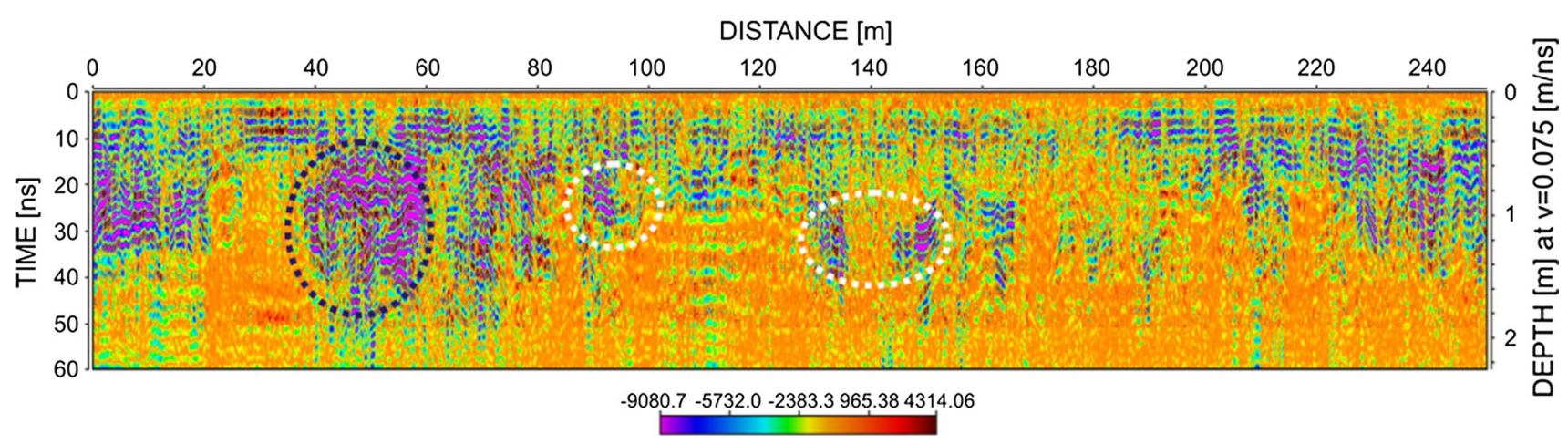

Fig. 9 Curvature gradient computed on profile 1. Anomalies probably connected with geomorphological deflection above oxbows are marked by dashed white lines. Main loosed zone is marked by black circle 
revealed that may indicate the earlier course of the Rudawa river bed (Fig. 9).

Grubbs filter threshold is the attribute that removes outliers from normally distributed data. It is a statistical test used to detect outliers in a univariate data set assumed to come from a normally distributed population. It is based on the assumption of normality.

The computed information from the Grubbs filter threshold has enhanced the elimination of random noise that may have obliterated the actual response. As in the case of curvature gradient, geomorphological deflections above oxbows are enhanced by Grubbs filter and marked in Fig. 10.

Convolve Prewitt is the attribute that returns a filtered response. The way it works is that input data are convolved with a three-dimensional kernel specified by filter type and associated parameters. Application of convolutional Prewitt operator for GPR data is presented by Peng and Zhao (2013) and Boniger and Tronicke (2012). In this article, we have used the Prewitt filter to emphasize the expected features of loosed zones (Fig. 11).

Dominant frequency is usually estimated by counting the number of relative maxima within some interval. These estimates depend on the phase of the data and tend to be higher than the zero-crossing frequency (Barnes 1993).

Dominant frequency (Fig. 12) shows us zones of smaller or larger interference, horizontal changes in lithology. Significant change in value of this attribute indicates transition from low-conductivity material to high-conductivity zones.

\section{Neural networks}

After characterizing the tested signal by using the above described attributes, an attempt was made to support the process of its interpretation and possibly also automatic classification using one of the artificial intelligence tools serving in computer-aided decision-making process. In this work, a tried-and-tested tool was chosen which ANN are.

Neural network can be taught with a teacher or can learn by itself. Self-learning neural networks (unsupervised) (Tadeusiewicz 2015; Mazurkiewicz et al. 2016) can be used for the initial or fully automatic, fast, low-cost classification of anomalous zones. However, as mentioned above, it is important that appropriate selection of attributes is made, due to the completely automatic learning scheme. After analyzing wide range of attributes provided by OpendTect

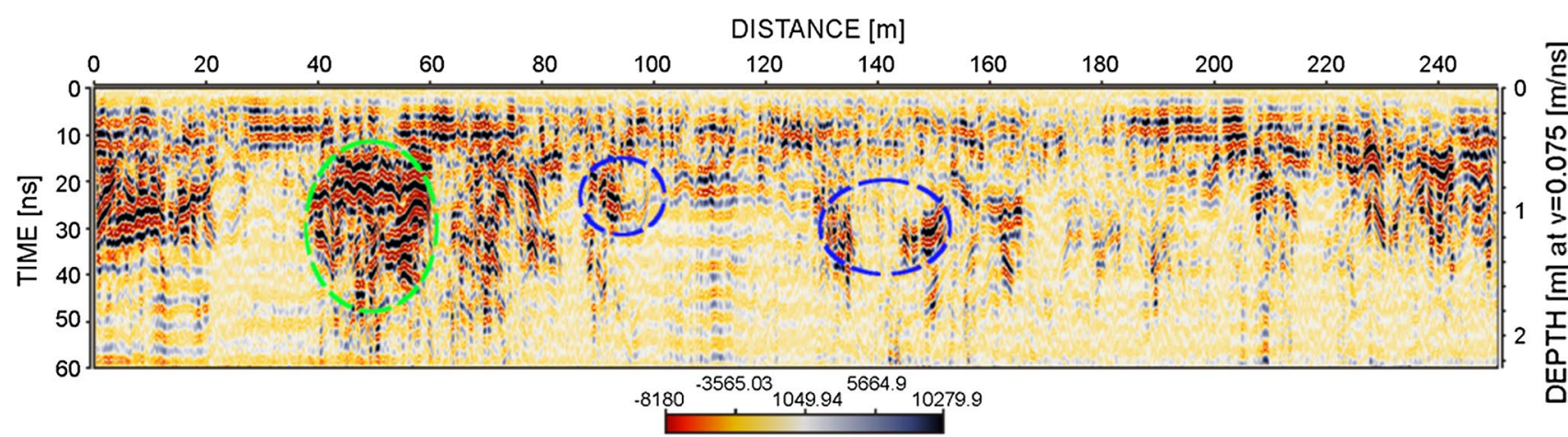

Fig. 10 Grubbs filter threshold for profile 1. Anomalies probably connected with geomorphological deflection above oxbows are marked by dashed blue lines. Main loosed zone is marked by green line

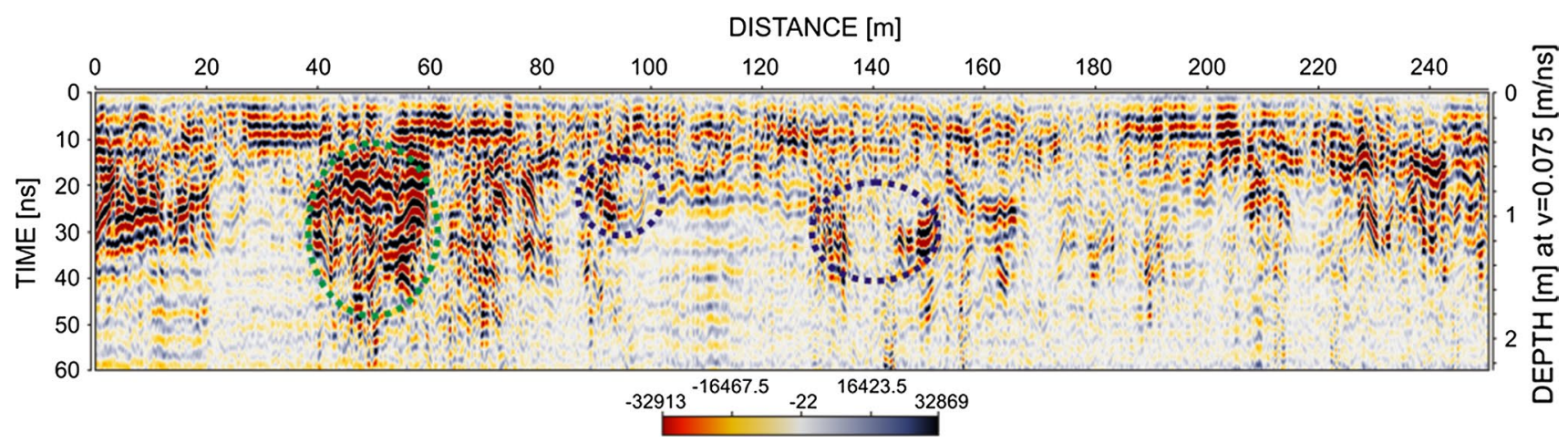

Fig. 11 Convolve Prewitt for profile 1. Anomalies probably connected with geomorphological deflections above oxbows are marked by dashed blue lines. Main loosed zone is marked by green line 


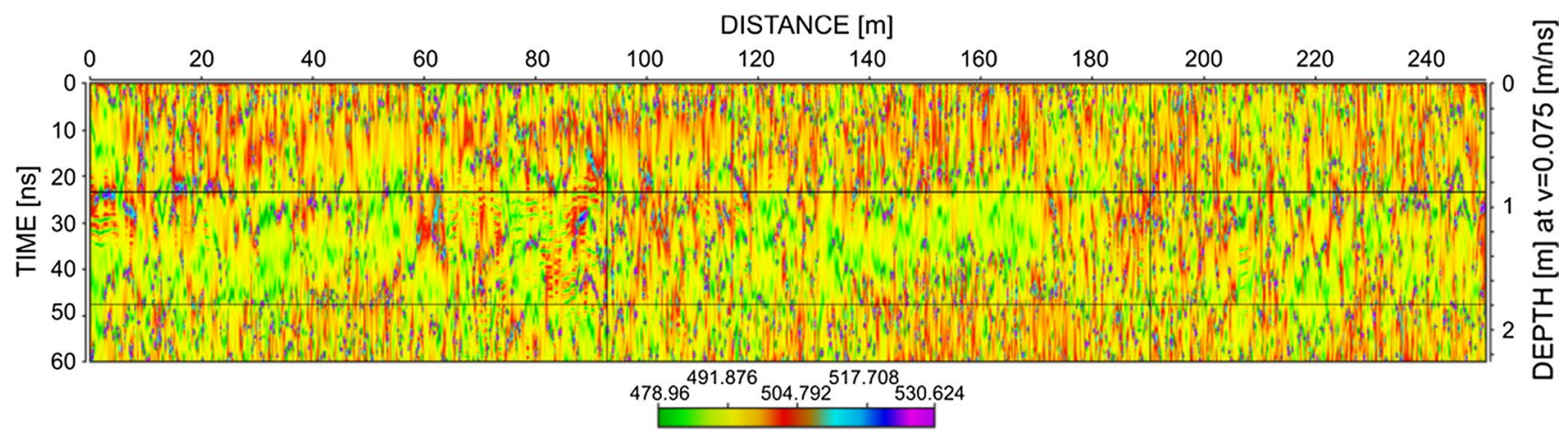

Fig. 12 Dominant frequency for profile 1. Significant change in value of this attribute indicates transition from low-conductivity material to high-conductivity zones

software, those presented earlier were chosen in this report as the best indicators of weakened zones in embankment structure, and then they were used as input to unsupervised neural networks. Additionally, set of randomly distributed points within the areas considered in the radargram were picked. Results of unsupervised neural networks classification is shown in Fig. 15. In the example, classification was made for four classes. The first class (blue) probably indicates high-frequency noise zones that have not been eliminated by processing. Second class (green) is connected with a stable part of embankments. Fourth class (pink) is probably connected with weak zones within embankment structure. Third class is practically unrepresented, so it is difficult to associate it with the specific feature of the medium under consideration. It can be seen that main weak zone is located between 40 and $60 \mathrm{~m}$ of the profile. Figure 15 shows certainty of classification.

The role of neuron networks taught "without supervisor" method based on grouping input data in such a way that groups of data are mutually similar to each other (clusters), while data groups that are little similar to each other or completely unlike each other are separated.

Because this is done using the unsupervised learning method, the creator of the network has no influence on how these groups are formed.

Neural network reveals the structure of the analyzed data, but does not penetrate into any causal relationship. After obtaining information about clusters detected by the network, it is necessary to analyze selected examples of data from individual clusters and interpret them (for example, GPR signals from embankments weakened zones).

The important thing is that the self-learning network (usually Kohonen's network is used here) will detect and indicate in a multidimensional attributes space of the grouped data, which can then be given the correct interpretation.

Neural network taught with a teacher (supervised) is the most commonly used method of neural network as an automatic classifier. In this area, the most often used are networks with feedforward of MLP type (multilayer perceptron), which can learn using backpropagation method. An example of its use in a similar task of classification can be found in Haduch and Tadeusiewicz (2018).

This more advanced method is necessary to define one set of peaks in the zones that is considered as to threaten the stability and resistance of the embankments and second set of picks outside these zones. Then, these sets were used as the so-called learning sets.

As the input for supervised neural networks classification, the same attributes as for unsupervised one were used. Additionally, two sets of picks were defined. First, one was picked in area of zone of high values of energy attribute (40-60 m of profile; $15-40 \mathrm{~ns}$ ), which was considered as loosen zone. Second, picks set was executed outside this zone. Results of classification give two classes. First one (pink areas in Fig. 13) shows probable distribution of weakened zones within embankment (pink areas show consolidated parts of the levee and blue anomalies depict the loose zones). Figures 15 and 16 show the similarity of matching the first and second classes.

Teaching neural networks by "teaching with a teacher" method (supervised learning) is a very effective method when we have a large and correctly defined training set; it means a set of input data for which the correct decision is known and can be considered as certain. This technique has found applicability in other fields of study such as in financial consulting or medical diagnostics described in the literature (Sasiada et al. 2017). However, in the problem of assessing the "condition" of flood embankments considered in this work, such a model training data was not existing because no information on the soil section of the surveyed embankments was known, where points of existing damage and structural changes (considered in the work), confirmed for example by drilling results. (There were not detailed information from geological wells and points of the geotechnical investigations.) For this reason, neural networks taught by the supervised learning method 


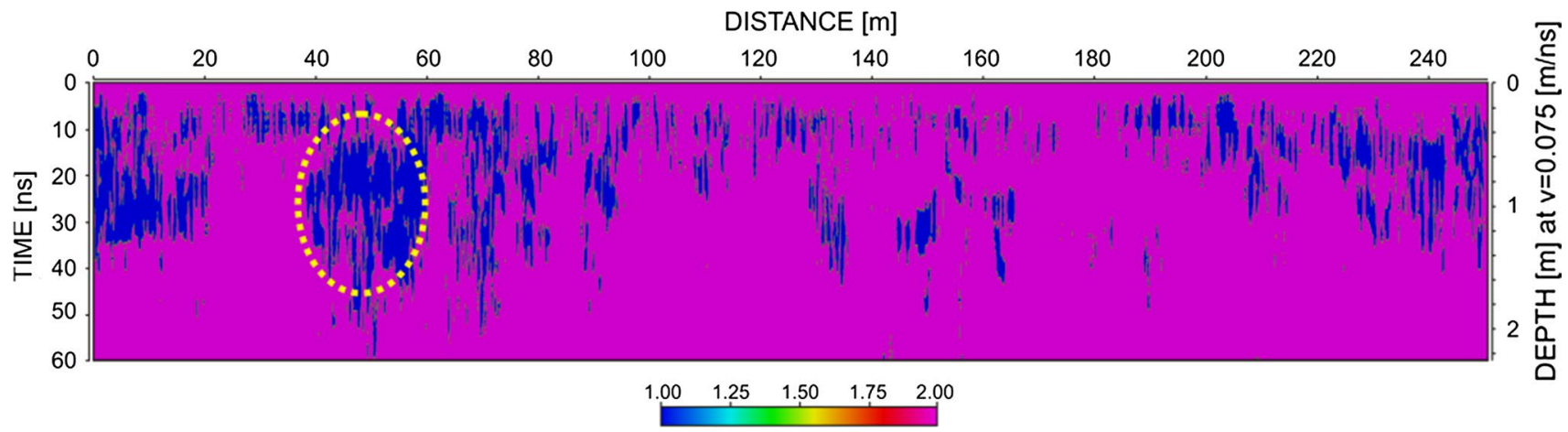

Fig. 13 Supervised classification results. Main loosed zone is marked by yellow dashed circle

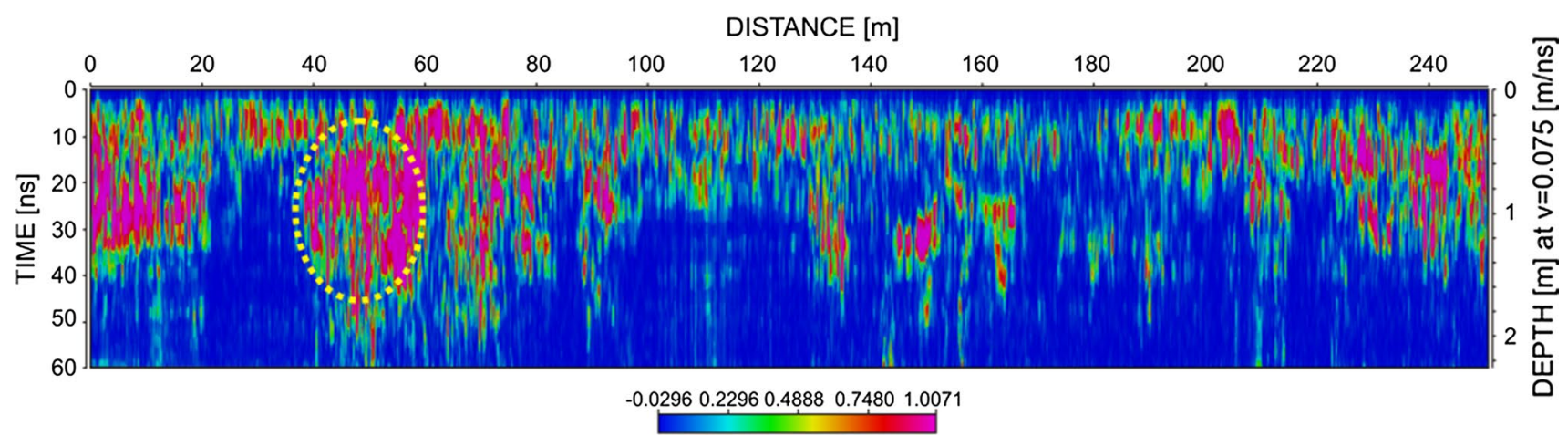

Fig. 14 Supervised classification-classification matching for high-energy zones. Main loosed zone is marked by yellow dashed circle

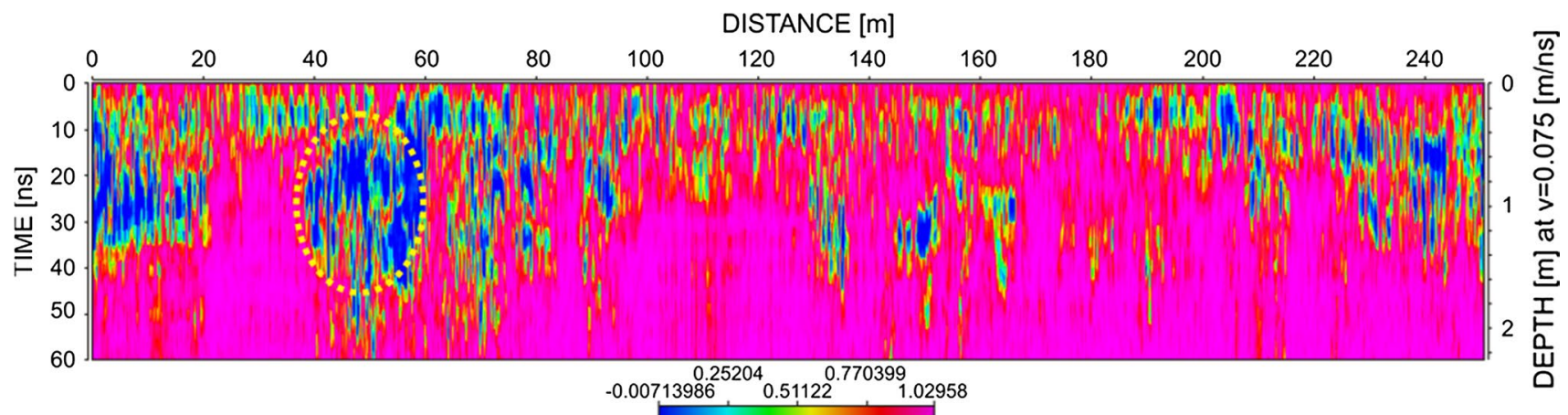

Fig. 15 Supervised classification-classification matching for weak energy zones. Main loosed zone is marked by yellow dashed circle

did not give sufficiently unambiguous results (Figs. 13, 14).

It should be noted that if we know with great probability the location of the weakened zone by performing quilting in it and teaching the neural network that it is a model, we can quite surely classify zones with similar features within the entire echogram.

The underlying idea of the paper is effective and efficient interpretation of GPR data. It is aimed at making interpretation more objective and thus enhanced reliability.
From the supervised approach in Fig. 13, it can be observed that zones of loosed and geomorphological variation are discernible (yellow broken circle). The neural network approach made this possible through the input of the computed attributes of the field data.

On the other hand, unsupervised neural network approach did not give same results but only recognized the loose zone. The discrepancy may be largely due to different underlying algorithms that performs the tasks. 


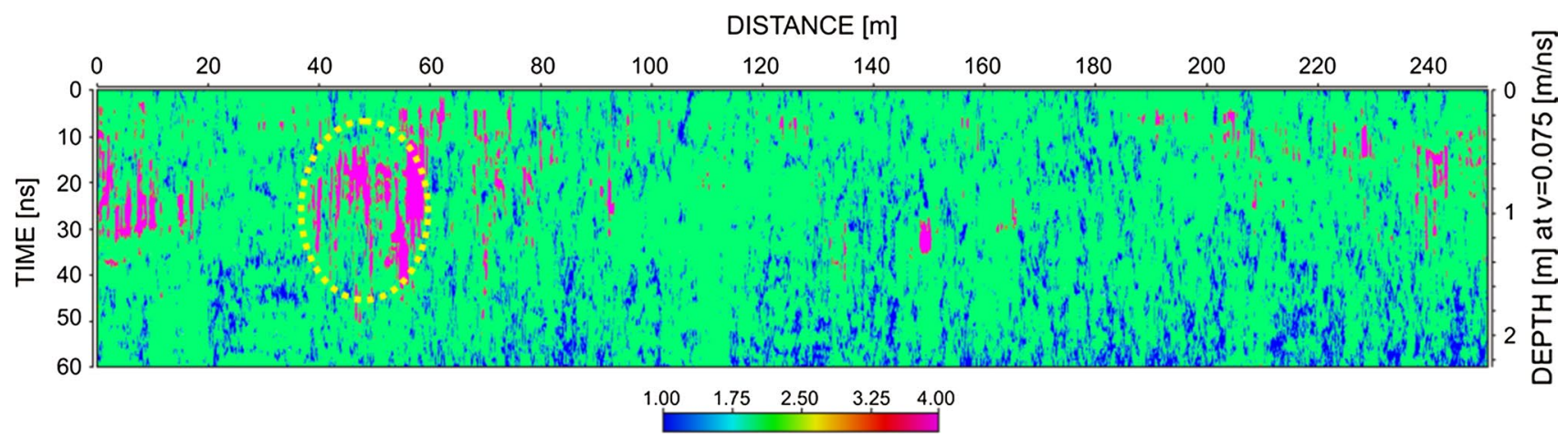

Fig. 16 Unsupervised classification-4 class. Main loosed zone is marked by yellow dashed circle

From the foregoing, it could be inferred that neural network has made possible the delineation of subtle but very vital information of the media through which the electromagnetic pulse energy propagated. Thus, better interpretation is enhanced and objectivity in interpretation is emplaced.

In this study, an attempt was made to use the network of taught without a teacher to solve the considered problem (unsupervised learning). Those networks analyze the internal self-similarity of data by detecting data that deviate from the majority. This method can be used to detect any anomalies in the data, so it can allow detection of zones in the embankments, whose internal structure is different from the average - and this may be a sought-after place for internal destruction of the embankment structure.

Comparison of Figs. 13, 14 and 15 with the original image shown in Fig. 5 suggests that what automatically detected by the use of neural networks approach is very similar to what an experienced geophysicist can discover by analyzing the GPR record visually. Therefore, it can be pointed out that the analysis using neural networks can be carried out completely automatically, which in the case of analyzing GPR signals on a long section of a flood embankment is a big advantage, compared to labor-intensive "manual" signal analysis.

Similar approach using neural networks for the analysis of biomedical signals with long activity records of specific organs (e.g., ECG recording in the Holter study or EEG registrations) signal changes has been found in the literature (Tadeusiewicz et al. 2013). The work emphasized on use of neural network in comparison with experienced physician. The problem was to detect exact location within a long signal where anomaly is located. The doctor was tired of looking through the long record without changes in pathology, so he may overlook these changes when they unexpectedly appear. In contrast, the neural network analysis of each signal fragments with the same accuracy and care and reliably detects signs of pathology. The same may be applied to long
GPR signal records for the analysis of flood embankments profile, which has proved effective. Essentially, when anomalies are encountered, the neural network detects and records it. This may be the basis or starting point for more detailed analysis made by specialist. It is on this premise that the method described in this article is based.

The results of GPR signal analysis obtained using the network taught "with the teacher" and "without the teacher" are presented in Figs. 16 and 17.

The results obtained using two different classifications methods are not exactly identical but compliment on each other. The zones that we associate with the weakening of the shaft structure are located in similar places for both methods. The discrepancy between classification results may be due to the method peak set definition for the supervised method. Peaks have been defined in a wide area of a high-energy zone, which may not be in fact weakened zone in its entire area, by which it can cause that part of the samples that are not actually associated with the weakened zone are classified into it. In the considered case, the classification method without a teacher gave the result more precisely indicating the location of the weakened zone.

\section{Conclusions}

In this research, the use of GPR to monitor and predict the strength of river embankment was considered. The results have shown the usefulness of GPR geophysical method through integration of ANN in the analysis of the data to characterize the materials of the embankment. Thus, weak zones within the embankment structure that are prone to encroachment by water are easily identified.

As it was shown in the paper, GPR technique has pointed out to the continuous information about condition of embankments between the points where control technical drilling were made. The article specifies the problem of creating a method of analyzing GPR signals aimed at detecting 


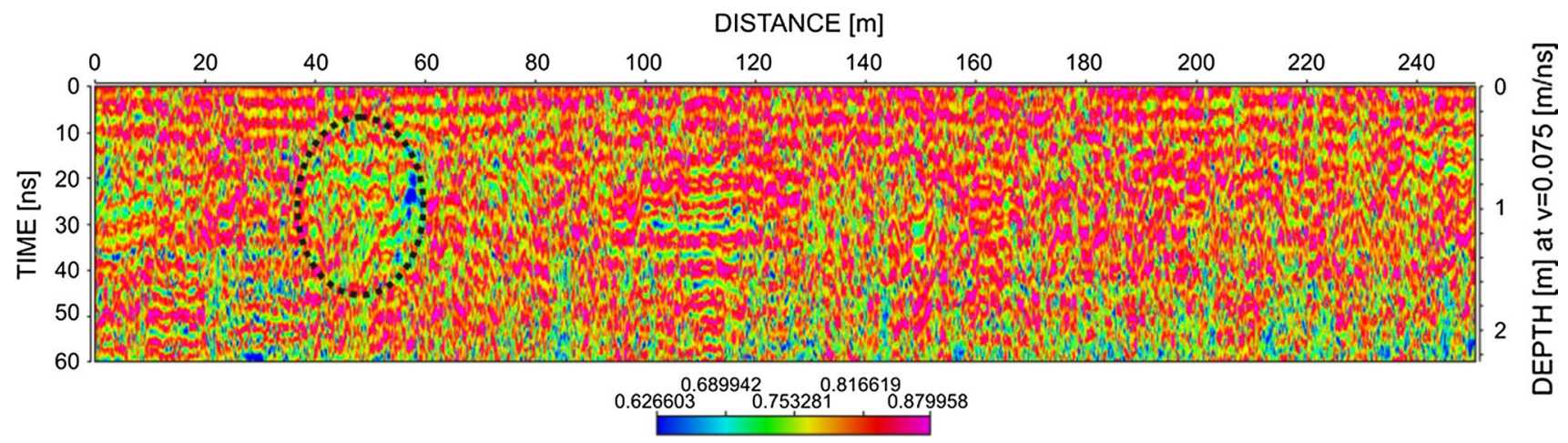

Fig. 17 Unsupervised classification-matching of classification. Main loosed zone is marked by black dashed circle

zones of weakness under the flood embankments. Methods of automatic recognition of elements of destruction restricting the strength of embankments were created.

Analysis of the results obtained using neural networks of scholars "with the teacher" allows to state that this technique gives the possibility of detecting and locating anomalies in the structure of the analyzed embankments. Detected anomalies are correctly located, and the clarity of the signal obtained using neural networks is better than on the original GPR record. The advantage of analysis carried out using neural networks is possibility to detect the presence of anomalies in an automatic way.

The zones that may indicate the earlier course of the Rudawa river have been revealed. Clear anomalies were recorded that could have originated from the geomorphological deflections above oxbows of the Rudawa river, flooded with different sediments of the oxbows. This statement may be a contribution to the research conducted by Krakow lovers reconstructing its former appearance.

The results of the conducted research confirm the results of previous historical works, perfectly complementing them. Although the areal extent of this study cover a small section of the studied reality, yet these sections can be expanded and included large ranges of research.

Generally speaking, it confirms the efficacy about the usefulness of GPR studies in other scientific fields of study, in particular those that do not belong to numerical sciences.

It should also be remembered that the GPR method applied before the commencement of construction works could prevent accumulation of additional works and costs by determining the usability of the built-in land. It should be noted that appropriate soil investigation is carried to avoid building on hidden oxbows that may not be visible to the surface. Therefore, the GPR method applied before construction works could prevent accumulation of additional works and costs by determining the usability of built-in land. Most importantly, the relatively low cost of GPR surveys would allow for the appropriate design of future construction works preventing the appearance of serious problems for users of buildings and roads in the future.

Acknowledgements The research was supported by AGH University of Science and Technology, as a science Project No. 11.11.140.645. I wish to appreciate the words of encouragement and inspiration from Professor Ryszard Tadeusiewicz in making the study a reality. I would like to extend my sincere thanks to Teresa Staszowska, Henryk Polański, Wiesław Sułowski, Akinniyi Akinsunmade and Paweł Pysz for helping in carrying out measurements. The paper was presented at the CAGG 2019 Conference "Challenges in Applied Geology and Geophysics" organized at the AGH University of Science and Technology, Krakow, Poland, 10-13 September 2019.

\section{Compliance with ethical standards}

Conflict of interest On behalf of all authors, the corresponding author states that there is no conflict of interest.

\section{References}

Anchuela Ó, Pueyo EL (2018) Internal characterization of embankment dams using ground penetrating radar (GPR) and thermographic analysis: a case study of the Medau Zirimilis Dam (Sardinia, Italy). Eng Geol 237:129-139

Annan AP (1999) Practical processing of GPR data. Sensor and Software Inc., Canada

Antoine R, Fauchard C, Fargier Y, Durand E (2015) Detection of leakage areas in an earth embankment from GPR measurements and permeability logging. Int J Geophys 2015:1-9

Barnes AE (1993) Instantaneous spectral bandwidth and dominant frequency with applications to seismic reflection data. Geophysics 58(3):419-428

Boniger U, Tronicke J (2012) Subsurface utility extraction and characterization: combining GPR symmetry and polarization attributes. IEEE Trans Geosci Remote Sens 50(3):736-746

Bradford JH, Wu Y (2007) Instantaneous spectral analysis: timefrequency mapping via wavelet matching with application to contaminated-site characterization by $3 \mathrm{D}$ GPR. Lead Edge 26(8):1018-1023

Catakli A, Mahdi H, Al Shukri H (2011) Texture analysis of GPR data as a tool for depicting soil mineralogy. In: 2011 IEEE applied imagery pattern recognition workshop (AIPR), IEEE, pp 1-8 
Chopra S (2007) Seismic attributes for prospect identification and reservoir characterization. Society of Exploration Geophysicists, Tulsa

Chopra S, Alexeev V (2005) Application of texture attribute analysis to 3D seismic data. CSEG Recorder, pp 29-32

DGB Beheer BV (2019) OpendTect user documentation version 6.4

Di Prinzio M et al (2010) Application of GPR to the monitoring of river embankments. J Appl Geophys 71(2-3):53-61

Everett ME (2013) Near-surface applied geophysics. Cambridge University Press, Cambridge

Gao D (2013) Integrating 3D seismic curvature and curvature gradient attributes for fracture characterization: methodologies and interpretational implications. Geophysics 78(2):021-031

Gołębiowski T, Małysa T (2018a) The application of non-standard GPR techniques for the examination of river dikes, technical transactions, $\mathrm{p} 7$

Gołębiowski T, Małysa T (2018b) Application of GPR method for detection of loose zones in flood levee. In: E3S web of conferences, vol 30. EDP Sciences

Gołębiowski T, Tomecka-Suchoń S, Farbisz J (2012) Zastosowanie kompleksowych metod geofizycznych do nieinwazyjnego badania stanu technicznego wałów przeciwpowodziowych, Współczesne problemy ochrony przeciwpowodziowej: sympozjum europejskie, Paryż-Orlean, pp 28-30

Gołębiowski T, Pasierb B, Porzucek S, Łój M (2018) Complex prospection of medieval underground salt chambers in the village of Wiślica, Poland. Archaeol Prospect 25(3):243-254

Haduch B, Tadeusiewicz R (2018) Neural networks as a tool to test the origin of motor gasoline. Przemysł Chemiczny 97(11):1843-1847 (in polish)

Hall-Beyer M (2012) GLCM texture tutorial. https://prism.ucalgary. ca/bitstream/handle/1880/51900/texture\%20tutorial\%20v\%20 3_0\%20180206.pdf?sequence $=11 \&$ isAllowed=y. Accessed 01 Apr 2019

Jarzyna J (2010) Geophysics in near surface investigations. Acta Geophys 58(1):1-4

Łanczont M, Madeyska T, Mrocze P, Hołub B, Żogała B, Bogucki A (2015) Relief and palaeorelief analyses of the Kraków Spadzista Palaeolithic site as the tools used for explanation of the site location. Quatern Int 359:89-95

Łój M, Porzucek S, Gołębiowski T, Everett ME (2018) Microgravimetric and GPR surveys for detection of unconsolidated zones in a levee. In: E3S web of conferences, vol 66. EDP Sciences, p 01022

Marcak H, Gołębiowski T, Tomecka-Suchoń S (2005) Analysis of possibility of using GPR refraction for location changes in river embankments. Geologia/Akademia Górniczo-Hutnicza im. Stanisława Staszica w Krakowie 31(3-4):259-274 (in polish)

Mazurkiewicz E, Tadeusiewicz R, Tomecka-Suchoń T (2016) Application of neural network enhanced ground-penetrating radar to localization of burial sites. Appl Artif Intell 30(9):844-860

McClymont AF et al (2008) Visualization of active faults using geometric attributes of 3D GPR data: an example from the Alpine Fault Zone, New Zealand. Geophysics 73(2):B11

Mori G (2009) The use of Ground Penetrating Radar and alternative geophysical techniques for assessing embankments and dykes safety. Ph.D. thesis

Nemytova OV, Rinkevich AB, Perov DV (2012) Instantaneous frequency estimation used for the classification of echo signals from different reflectors. Russ J Nondestruct Test 48(11):649-661

Peng TY, Zhao Y (2013) CUDA-based parallel Prewitt algorithm implementation and its application on GPR. Appl Mech Mater 380:4002-4006
Perri MT et al (2014) River embankment characterization: the joint use of geophysical and geotechnical techniques. J Appl Geophys 110:5-22

Rich JP (2008) Expanding the applicability of curvature attributes through clarification of ambiguities in derivation and terminology. In: 78th annual international meeting, SEG, expanded abstracts, pp 884-888

Rich JP, Marfurt K (2013) Curvature gradient attributes for improved fault characterization. In: SEG Houston annual meeting, pp $1319-1323$

Sandmeier KJ (2012) Reflexw 6.0 manual sandmeier software. Karlsruhe, Germany

Sasiada M, Fraczek-Szczypta A, Tadeusiewicz R (2017) Efficiency testing of artificial neural networks in predicting the properties of carbon nanomaterials as potential systems for nervous tissue stimulation and regeneration. Bio-Algorithms Med-Syst 13(1):25-35

Sieinski E et al (2015) Wykonanie pomiarów, badania i ocean stanu technicznego i stanu bezpieczeństwa wałów przeciwpowodziowych stanowiących własność Skarbu Państwa: Wał prawy i lewy rzeki Rudawy. Warszawa (in polish)

Słowik M (2011) Changes of river bed pattern and traces of anthropogenic intervention: the example of using GPR method (the Obra River, western Poland). Appl Geogr 31(2):784-799

Szymczyk P, Marcak H, Tomecka-Suchoń S, Szymczyk M, Gajer M, Gołębiowski T (2014) Zaawansowane metody przetwarzania danych georadarowych oraz automatyczne rozpoznawanie anomalii w strukturach geologicznych. Elektronika: konstrukcje, technologie, zastosowania 55(12):56-61

Szymczyk P, Marcak H, Tomecka-Suchoń S, Szymczyk M, Gajer M, Gołębiowski T (2015a) Komputerowe przetwarzanie i analiza danych georadarowych. Wydawnictwo Naukowe IAE

Szymczyk P, Tomecka-Suchoń S, Szymczyk M (2015b) Neural networks as a tool for georadar data processing. Int J Appl Math Comput Sci 25(4):955-960

Tadeusiewicz R (2015) Neural networks in mining sciences: general overview and some representative examples. Arch Min Sci 60(4):971-984

Tadeusiewicz R, Korbicz J, Rutkowski L, Duch W(2013) Neural Networks in Biomedical Engineering: Siecineuronowe w inżynierii biomedycznej: Inżynieria biomedyczna—podstawy i zastosowania vol. 9 in monograph: biomedical engineering-basics and applications, Exit, Warszawa 2013 (in polish)

Tanajewski D, Bakuła M (2016) Application of ground penetrating radar surveys and GPS surveys for monitoring the condition of Levees and Dykes. Acta Geophys 64(4):1093-1111

Taner MT (2001) Seismic attributes. CSEG Recorder, pp 48-56

Taner MT, Koehler F, Sheriff RE (1979) Complex seismic trace analysis. Geophysics 44(6):1041-1063

Tomecka-Suchoń S (2012) Georadar studies on St. Benedict's Church on Lasota Hill, Kraków, Poland. Acta Geophys 60(2):386-398

Tomecka-Suchoń S, Gołębiowski T, Dec J et al (2019) Application of GPR and seismic methods for noninvasive examination of glacial and postglacial sediments in the Psia Trawka glade: the Tatra Mts., Poland. Acta Geophys. https://doi.org/10.1007/s1160 0-019-00334-X

$\mathrm{Xu}$ X et al (2010) GPR detection of several common subsurface voids inside dikes and dams. Eng Geol 111(1-4):31-42

Zhao W et al (2013) Ground penetrating radar (GPR) attribute analysis for archaeological prospection. J Appl Geophys 97:107-117

Zhao W, Forte E, Pipan M (2016) Texture attribute analysis of GPR data for archaeological prospection. Pure Appl Geophys 173(8):2737-2751 